\title{
ANEMIA HEMOLITIK AKIBAT ENDOKARDITIS KATUP AORTA PADA PEREMPUAN DEWASA DENGAN PATENT DUCTUS ARTERIOSUS
}

\author{
Andi Tihardimanto Kaharuddin ${ }^{1}$, Miswani Mukani Syuaib ${ }^{2}$, Pendrik Tandean ${ }^{3}$ \\ ${ }^{I}$ Bagian Kardiologi dan Kedokteran Vaskuler, Fakultas Kedokteran dan Ilmu Kesehatan Universitas \\ Islam Negeri Alauddin Makassar \\ ${ }^{2}$ Bagian Fisiologi, Fakultas Kedokteran dan Ilmu Kesehatan Universitas Islam Negeri Alauddin \\ Makassar \\ ${ }^{3}$ Bagian Kardiologi dan Kedokteran Vaskuler, Fakultas Kedokteran Universitas Hasanuddin Makassar
}

\begin{abstract}
Abstrak
Patent ductus arteriosus (PDA) adalah kelainan jantung bawaan dimana duktus arteriosus tetap terbuka. Pada usia dewasa, PDA jarang ditemukan karena biasanya ditemukan dan diterapi selama masa kanak-kanak. Endokarditis infektif adalah salah satu komplikasi utama dari PDA. Anemia hemolitik bukanlah gejala umum pada endokarditis infektif dan hanya dilaporkan dalam beberapa laporan kasus. Kami melaporkan kasus anemia hemolitik pada wanita dengan PDA dan endokarditis katup aorta. Dilaporkan seorang perempuan, 44 tahun, masuk rumah sakit dengan keluhan sesak napas yang dirasakan sejak 2 bulan terakhir dan memberat 8 jam sebelum masuk rumah sakit. Sesak bertambah saat beraktivitas dan berbaring terlentang. Demam hilang timbul dan berat badan pasien dirasakan menurun dalam 2 bulan terakhir. Dari pemeriksaan fisis dan penunjang didapatkan adanya anemis, tanda-tanda pembesaran jantung yang disertai PDA dan aorta regurgitasi berat, serta tes Coomb positif.

Pasien kemudian diterapi untuk eradikasi kuman endokarditis, mengurangi gejala gagal jantung, dan anemia hemolitik, diantaranya antibiotic, diuretik, Ace inhibitor, dan steroid. Pembedahan diindikasikan pada pasien ini untuk menghilangkan jaringan jantung yang terinfeksi, menutup PDA, dan mengganti katup aorta.
\end{abstract}

Kata Kunci : Anemia hemolitik, patent ductus arteriosus, endokarditis, aorta regurgitasi

\section{Pendahuluan}

Patent Ductus Arteriosus (PDA) adalah penyakit jantung bawaan dimana duktus arteriosus yang menghubungkan arteri pulmonal dan aorta tetap terbuka ${ }^{(1)}$. Banyak faktor yang mempengaruhi terjadinya PDA diantaranya adalah prematur. Prematuritas merupakan salah satu faktor yang dapat menyebabkan terjadinya PDA dan prevalensinya lebih tinggi dibandingkan dengan bayi aterm ${ }^{(2)}$.

PDA merupakan kasus yang jarang ditemukan pada orang dewasa. Dari studi yang dilakukan oleh Campbell, tentang perjalanan penyakit PDA, bahwa setelah usia 2 tahun, angka kematian per tahun di antara pasien dengan PDA adalah sekitar $0,5 \%$, usia 20 tahun, $1-1,5 \%$, selama dekade ketiga kehidupan, 2-2,5\%, pada dekade keempat sekitar 4\%. Dari studi ini terlihat bahwa semakin lambat PDA didiagnosis maka akan semakin tinggi tingkat kematian. Hal ini diakibatkan karena banyak faktor yaitu terjadinya hipertensi pulmonal, gagal jantung akut dan endokarditis ${ }^{(3)}$. Adapun salah satu akibat dari endokarditis adalah insufisiensi pada katup jantung terutama katup aorta. Anemia hemolitik akibat endokarditis bukanlah kelainan yang umum 
terjadi dan hanya dilaporkan dalam beberapa laporan kasus saja ${ }^{(4)}$.

\section{Latar Belakang Kasus}

Seorang perempuan, 44 tahun, masuk ke rumah sakit dengan keluhan lemas yang dirasakan sejak 2 bulan terakhir. Sesak napas juga muncul dan dirasakan sejak sejak 3 minggu sebelum masuk rumah sakit. Pasien mengeluh sesak napas memberat ketika sedang beraktivitas berat. Pasien merasakan bertambah sesak pada posisi terlentang. Pasien juga sering terbangun pada malam hari karena sesak napas. Riwayat sesak napas sebelumnya dirasakan sejak 2 bulan yang lalu. Batuk berlendir sejak 3 minggu yang lalu, lendir warna putih. Riwayat demam sebelumnya ada 3 bulan terakhir bersifat hilang timbul tanpa konsumsi obat penurun demam. Berat badan dirasakan menurun dalam 2 bulan terakhir. Riwayat penyakit biru selama masa kecil tidak ada dan menurut pasien tidak memiliki penyakit yang serius.

\section{$\underline{\text { Riwayat penyakit }}$}

Pasien telah didiagnosis 2 bulan dengan gagal jantung, aorta regurgitasi, dan endokarditis.

Riwayat kelahiran

Ibu pasien berusia 21 tahun saat melahirkan pasien. Pasien lahir cukup bulan, berat badan lahir tidak diketahui. Persalinan dilakukan oleh dukun beranak di rumah.
Selama proses kehamilan dan persalinan tidak ada komplikasi yang terjadi.

$\underline{\text { Riwayat psikososial }}$

Pasien merupakan anak pertama dari tiga bersaudara, sehari-hari bekerja sebagai ibu rumah tangga. Saat ini pasien memiliki empat orang anak dengan riwayat persalinan spontan per vaginam.

\section{Diagnosis}

Diagnosis ditegakkan berdasarkan anamnesis, pemeriksaan fisis, dan penunjang. Dari anamnesis, didapatkan adanya gejala gagal jantung kongestif seperti sesak napas saat beraktivitas, berbaring terlentang, dan sering terbangun saat malam hari karena sesak. Dari pemeriksaan fisis didapatkan konjungtiva anemis, peningkatan desakan vena sentral, ronki di basal kedua paru, bising mid to late diatolik grade 2/4 di right upper sternal border, bising kontinu di left upper sternal border grade 3/6 dan bising sistolik di apex grade 3/6. Pada pemeriksaan abdomen peristaltik kesan normal. Edema pada kedua dorsum pedis minimal.

Hasil pemeriksaan laboratorium Hemoglobin $6.9 \mathrm{gr} / \mathrm{dl}$, retikulosit $4.86 \%$, tes Coomb positif $(+2)$ dan tidak ada pertumbuhan bakteri pada pemeriksaan kultur darah. Pada pemeriksaan foto rontgen dada ditemukan kardiomegali, tanda kongesti paru, dan pneumonia 
spesifik. Ekokardiogram (gambar 1) menunjukkan fungsi sistolik ventrikel kiri normal dengan fraksi ejeksi 59\%, dilatasi atrium kiri dan ventrikel, mitral regurgitasi sedang, aorta regurgitasi berat disertai vegetasi ukuran $1.2 \times 0.5 \mathrm{~cm}$, dan PDA diameter $0.37 \mathrm{~cm}$ dengan kesan pirau kiri ke kanan.

\section{Tatalaksana}

Pada pasien, diberikan tatalaksana konservatif, yaitu untuk penanganan gagal jantung kongestif, endokarditis, regurgitasi aorta, dan anemia hemolitik. Tatalaksana untuk gagal jantung kongestif diberikan terapi diuretik, furosemide $40 \mathrm{mg}$ tiap 8 jam via intravena dan Ace inhibitor, Captopril $6.25 \mathrm{mg}$ tiap 8 jam per oral, dan $\beta$-blocker, bisoprolol $1.25 \mathrm{mg}$ tiap 24 jam per oral. Pasien diberikan terapi antibiotik, Doksisiklin $200 \mathrm{mg}$ tiap 24 jam per oral sebagai terapi lanjutan endokarditis pada perawatan sebelumnya. Kortikosteroid juga diberikan untuk penanganan anemia hemolitiknya. Terapi bedah diindikasikan pada pasien ini dengan tujuan untuk menyingkirkan jaringan yang terinfeksi dan rekonstruksi morfologi katup jantung, termasuk memperbaiki atau mengganti katup yang terpengaruh.

\section{Follow up dan Outcome}

Terapi yang diberikan pada pasien memberikan respon yang cukup baik. Tanda-tanda kongestif akibat gagal jantung sangat berkurang dibandingkan saat pasien masuk rumah sakit. Penyebab anemia hemolitik yang terjadi pada pasien ini kemungkinan akibat shear stress pada katup aorta yang disertai vegetasi sehingga menyebabkan destruksi dari eritrosit. Oleh karena itu, terapi utama untuk anemia hemolitik pada pasien ini adalah menghilangkan vegetasi yang ada akibat endokarditisnya.

\section{Diskusi}

Berdasarkan anamnesis, pemeriksaan fisis, dan penunjang, pasien didiagnosis PDA, gagal jantung kongestif, endokarditis, dan anemia hemolitik. PDA adalah suatu kondisi dimana terjadi kegagalan penutupan duktus arteriosus secara permanen. Duktus arteriosus berkembang dari bagian distal lengkung arkus aorta dan menghubungkan arteri pulmonalis dengan aorta desendens. Setelah lahir, duktus akan tertutup oleh kontraksi otot polos medial yang menyebabkan penyempitan, pemendekan dan penutupan lumen secara permanen untuk membentuk ligamentum arteriosus. Kegagalan penutupan duktus menyebabkan duktus tetap terbuka. Bentuk dari PDA bervariasi, namun sebagian besar 
ujung aorta lebar dan menyempit menuju ke ujung pulmonal. Pada pasien ini, etiologinya masih belum dapat dijelaskan. Hal ini disebabkan kurangnya data antenatal dan persalinan yang tidak dilakukan oleh pihak medis.

Pada pasien ini, PDA baru diketahui pada usia dewasa. Sebelumnya pasien tidak memiliki keluhan. Pasien baru mengetahui kelainan ini melalui pemeriksaan ekocardiografi saat dirawat di rumah sakit. Dari perspektif klinis, PDA persisten selama masa dewasa dapat diklasifikasikan silent PDA, PDA kecil, sedang, dan besar (5). Dalam kasus ini pasien dapat dikategorikan PDA sedang karena didapatkan bising continuous, pembesaran atrium kiri dan ventrikel kiri, hipertensi pulmonal tetapi tidak didapatkan tanda Eisenmenger. Menurut klasifikasi berdasarkan ukuran PDA, pada pasien ini dapat diklasifikasikan sebagai PDA sedang karena ukuran PDA yang didapatkan sebesar $3 \mathrm{~mm}$.

Selain itu, pada pasien ini juga terdapat aorta regurgitasi kemungkinan besar diperberat oleh endokarditis infektif yang terjadi pada katup aorta (6). Endokarditis infektif biasanya lebih jarang ditemukan pada perempuan, seperti pada pasien ini. Berbagai macam jenis bakteri dan jamur dapat menyebabkan endokarditis infektif. Gram positif kokus merupakan penyebab yang paling sering termasuk diantaranya adalah streptococcus, staphylococcus dan enterococcus. Modified Duke Criteria mengelompokan ketiga patogen ini sebagai "mikroorganisme tipikal" sebagai kriteria mayor dari kultur darah yang positif ${ }^{(7)}$.

Patogenesis dari endokarditis infektif pada pasien ini adalah adanya predileksi yaitu patent ductus arteriosus yang mengakibatkan turbulensi aliran darah. Turbulensi darah menyebabkan disrupsi endotel, kerusakan endotel menyebabkan aktivasi platelet sehingga terjadi deposisi platelet. Selain itu terjadi juga aktivasi kaskade koagulasi sehingga terbentuk fibrin. Lesi ini disebut nonbacterial thrombotic endokarditis (NBTE) yang berperan sebagai nidus bagi adhesi bakteri atau fungi pada aliran darah. Pada pasien ini terdapat nidus pada katup jantung sehingga paparan terhadap mikroorganisme seperti paparan nosokomial, prosedur dental, infeksi pada telinga atau infeksi traktus respiratorius menyebabkan nidus tersebut berkembang menjadi suatu vegetasi yang besar pada katup aorta. Pada pasien ini, faktor risiko paparan mikroorganisme kemungkinan berasal dari infeksi traktus respirotorius yang tampak pada pemeriksaan foto toraks.

Pada pemeriksaan laboratorium didapatkan anemia dengan tes Coomb 
positif yang menandakan adanya anemia hemolitik autoimun. Penyebab anemia hemolitik pada pasien ini kemungkinan diakibatkan oleh shear stress yang terjadi di sepanjang vegetasi pada katup aorta sehingga menyebabkan destruksi dari eritrosit secara berlebihan. Selain itu, faktor otoimun turut berperan terhadap progresifitas hemolitik yang terjadi. Oleh karena itu, selain transfuse jika diindikasikan, pemberian imunosupresan juga perlu diberikan pada pasien ini.

Ekokardiogram adalah prosedur pilihan untuk memastikan diagnosis dan mengkarakterisasi PDA. Dalam kaitannya dengan implikasi klinis, echocardiogram dapat berguna dalam mengklasifikasikan PDA sebagai silent, kecil, sedang, atau PDA besar. Selain mengevaluasi duktus arteriosus, ekokardiografi digunakan untuk mengidentifikasi dan mengevaluasi kelainan jantung lainnya.

Tindakan lanjut pada pasien ini yaitu tindakan kateterisasi jantung karena dari pemeriksaan ekokardiogram ditemukan kecenderungan tinggi untuk kejadian hipertensi pulmonal. Tes ini dilakukan untuk menentukan dapat atau tidaknya terapi intervensi dilakukan melalui tes vasoreaktivitas dengan oksigen atau nitrit oksida ${ }^{(8)}$. Dari tindakan ini dapat juga menilai struktur anatomi dan fisiologis dan untuk tindakan intervensi lanjut. Selain itu kateterisasi jantung dapat menilai pulmonary vascular resistance (PVR), fungsi diastolik ventrikel kiri dan kanan menilai tekanan gradien dan shunt, angiografi koroner dan untuk evaluasi pembuluh darah di ekstrakardiak seperti $\operatorname{arteri~kolateral~}^{(9)}$.

Penutupan duktus ditujukan untuk anak atau orang dewasa yang simtomatik dengan shunting kiri-ke-kanan yang signifikan melalui PDA. Pada pasien asimtomatik dengan shunting kiri-ke-kanan yang signifikan yang menyebabkan pembesaran jantung kiri, penutupan diindikasikan untuk meminimalkan risiko komplikasi di masa depan. Pada pasien dengan gangguan struktural dan kecenderungan hipertensi pulmonal, sebelum dilakukan tindakan penutupan duktus perlu dilakukan tindakan kateterisasi jantung kanan untuk menilai status hemodinamik pasien, struktur anatomis dari PDA, dan resistensi pulmonal (10)

Pada pasien ini, diberikan pula terapi empiris antibiotik untuk endokarditisnya. Pada perawatan sebelumnya, pasien telah diberikan antibiotik kombinasi Ceftrixone dan Gantamicin injeksi selama 2 minggu kemudian dilanjutkan dengan Doksisiklin 200 mg sekali sehari. Pemberian antibiotik oxacillin sebaiknya ditambahkan sebagai 
bagian dari terapi empiris pada pasien dengan katup natif. Jika didapatkan alergi terhadap penisilin, vancomycin dapat menjadi pilihan. Gagal jantung pada pasien ini mengakibatkan kongestif paru sehingga untuk mengurangi kongesti diberikan terapi diuretik dan pemberian Ace inhibitor.

Indikasi terapi operatif diantaranya adalah obstruksi katup akibat vegetasi, pasien mitral atau aorta regurgitasi berat tanpa gagal jantung tetapi disertai dengan tanda-tanda peningkatan tekanan end diastolik, tekanan atrium kiri yang tinggi atau hipertensi pulmonal sedang hingga berat baik pada katup natif ataupun prostetik.

Pada beberapa kasus, antibiotik saja tidak cukup untuk mengeradikasi infeksi. Terapi bedah diindikasikan ketika demam dan kultur darah yang positif menetap selama beberapa hari ( 7 hingga 10 hari) walaupun telah mendapatkan antibiotik yang adekuat dan ketika ada abses ekstrakardiak (splenik, vertebral, serebral, renal) dan penyebab demam lainnya telah disingkirkan. Tanda-tanda infeksi lokal yang tidak terkontrol termasuk penambahan ukuran vegetasi, terbentuknya abses, aneurisma dan fistula. Peranan terapi bedah dalam mencegah kejadian embolik masih kontroversial. Terapi bedah diindikasikan pada vegetasi yang persisten dengan ukuran $10 \mathrm{~mm}$ setelah satu atau lebih kejadian silent embolic. Terapi bedah dapat dipertimbangkan pada vegetasi berukuran besar lebih dari $15 \mathrm{~mm}$. Terapi bedah untuk pencegahan emboli sebaiknya dilakukan dini, saat beberapa hari sesudah dimulainya antibiotik, dimana risiko embolik adalah tertinggi pada saat ini.

Objektif utama dari terapi bedah adalah membuang jaringan yang terinfeksi dan rekonstruksi morfologi katup jantung, termasuk memperbaiki atau mengganti katup yang terpengaruh. Jika infeksi terbatas pada leaflet atau kuspis, baik metode untuk memperbaiki atau mengganti katup dapat digunakan. Akan tetapi, memperbaiki katup (valve repair) lebih dipilih jika memungkinkan, terutama jika endokarditis melibatkan katup tanpa destruksi yang signifikan. Perforasi dari katup atau leaflet dapat diperbaiki dengan pericardial patch. Penggunaan prostesis mekanik ataupun biologik memiliki mortalitas operatif yang sama. Transplantasi jantung dapat dipertimbangkan pada kasus ekstrim dimana prosedur operatif berulang gagal mengeradikasi infektif endokarditis.

\section{Kesimpulan}

Telah dilaporkan sebuah kasus seorang perempuan 44 tahun masuk rumah sakit dengan keluhan sesak napas yang dirasakan sejak 2 bulan terakhir disertai 
batuk berlendir sejak 3 minggu yang lalu, demam hilang timbul, dan berat badan menurun dalam 2 bulan terakhir. Dari pemeriksaan fisis didapatkan peningkatan desakan vena sentral dan terdengar bising kontinyu di area pulmonal. Dari pemeriksaan penunjang didapatkan anemia dengan tes Coomb positif, EKG dengan LVH, foto thorax didapatkan kesan kardiomegali, tanda-tanda bendungan paru, dan pneumonia spesifik. Pada pemeriksaan ekokardiografi didapatkan patent duktus arteriosus dengan diameter $0.3 \mathrm{~cm}$ dan aorta regurgitasi berat dengan vegetasi di katup aorta. Berdasarkan anamnesis, pemeriksaan fisis dan penunjang pasien ini dikategorikan sebagai moderate patent ductus arteriosus, gagal jantung kongestif, aorta regurgitasi berat, endokarditis, dan anemia hemolitik. Pasien kemudian diberikan terapi untuk mengurangi kongestif dan eradikasi kuman endokarditisnya yang selanjutnya dilakukan intervensi bedah untuk menyingkirkan jaringan infektif, menutup PDA, dan penggantian katup aorta.

Pembelajaran pada kasus ini adalah pasien dengan kelainan jantung bawaan yang tidak dikoreksi hingga dewasa dapat menimbulkan beberapa komplikasi serius saat dewasa yang penatalaksanaannya membutuhkan tindakan intervensi yang lebih besar dan berisiko.

\section{Daftar Pustaka}

1. Wiyono S, Witsenburg M, Hesselink J. 2008 , 'Patent Ductus Arteriosus in Adults, Neth Heart J, vol 16, no.7, hh. 255-259.

2. Cassidy H, Cassidy L, Blacksbear J. 2009, 'Incidental Discovery of a Patent Ductus Arteriosus in Adults', $J$ Am Board Fam Med, vol 22, no.2, hh 214218.

3. Kalavrouziotis G, Kourtesis A, Paphitis C, Azariades P. 2010, 'Closure of a Large Patent Ductus Arteriosus in Children and Adults with Pulmonary Hypertension', Helenic J Cardiol, vol 51, hh.15-18.

4. Koc F, Bekar L, Kadi H, Ceyhan K. 2010, 'Hemolysis and Infective Endokarditis in a Mitral Prosthetic Valve', Arch Turk Soc Cardiol ; 38(6):429-431

5. Wu J, Child J. 2004, 'Common Congenital Heart Disorders in Adults', Curr Probl Cardiol, vol 29, hh.657661.

6. Stout KK, Verrier ED. 2009. 'Acute Valvular Regurgitation. Circulation;119:3232-3241.

7. Habib G, Lancelotti P, Antunes M, et al. 2015. ESC Guidelines for the Management of Infective Endokarditis. Eur Heart J:1-54 
8. Bonhoeffer P, Groot N, Haan F 2010, 'ESC Guidelines for the Management of Grown-up Congenital Heart Disease' Eur Heart J. vol 31, hh.2927-2930.

9. Warnes C, Williams R, Bashore T. 2008, 'ACC/AHA Guidelines for the Management of Adults With Congenital Heart Disease: Executive Summary', Circulation, vol 118, hh. 2414-2415.

10. Mori Y 2012, 'Transcatheter closure of Patent Ductus Arteriosus in Adults', JCCASE, hh. 90-91. 

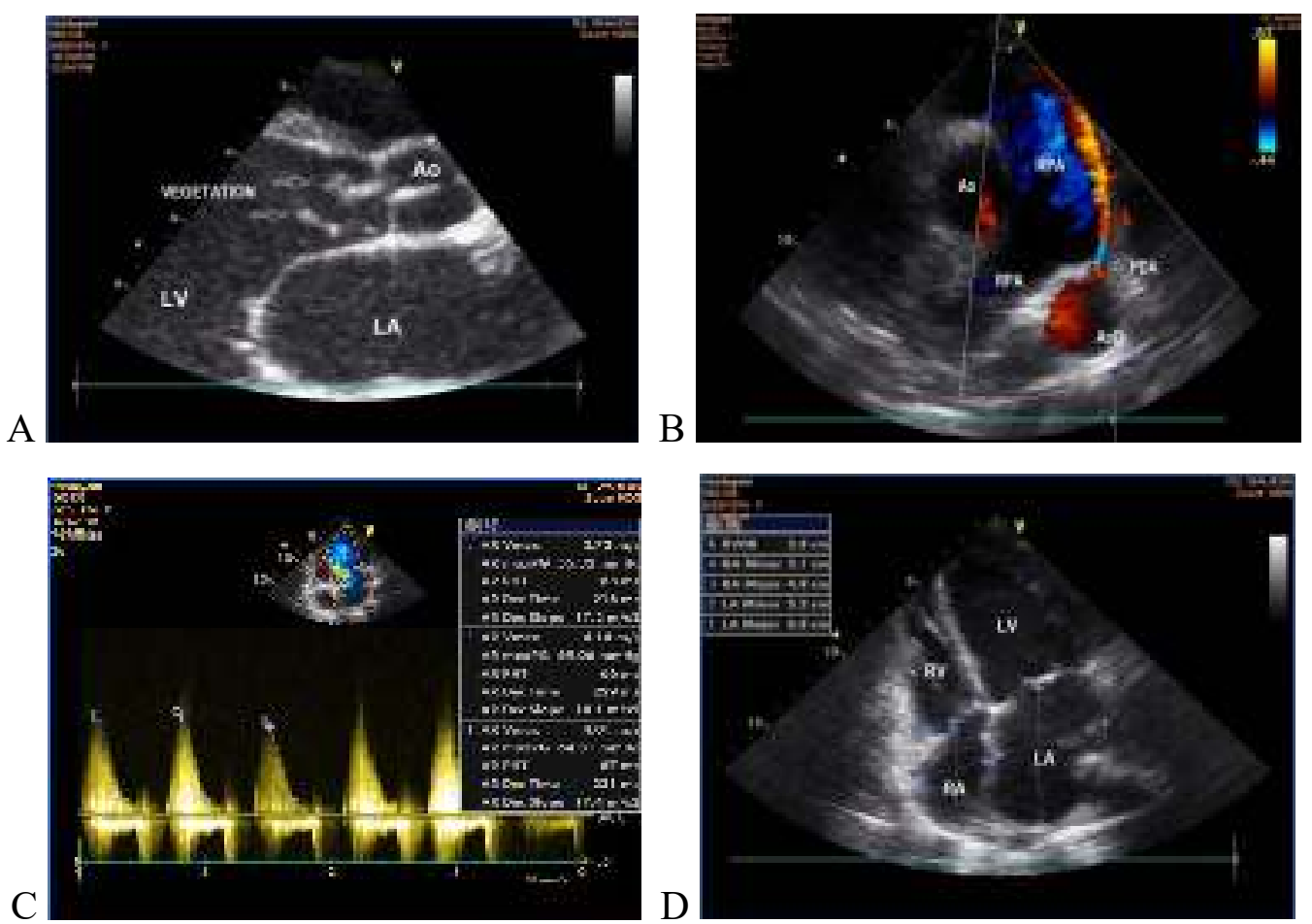

Gambar 1. Ekokardiogram (A) potongan PLAX menunjukkan vegetasi pada katup aorta; (B) potongan PSAX setinggi aorta menunjukkan PDA; (C) pengukuran severitas regurgitasi aorta; (D) potongan $\mathrm{A} 4 \mathrm{C}$ menunjukkan dilatasi atrium dan ventrikel kiri 